\title{
Fiziksel Aktivite Değerlendirmesi: Subjektif ve Objektif Yöntemler
}

\author{
Physical Activity Assessment: Subjective and Objective Methods
}

İsmet TÜMTÜRK ${ }^{1}$ (iD), Fatih ÖZDEN² (iD), Mehmet ÖZKESKİN

ÖZ

Fiziksel aktivite genel sağlık durumu ile ilişkili önemli bir parametredir. Son zamanlarda, karantina önlemlerinin alındığı Covid-19 pandemisi sebebiyle artan fiziksel inaktivite eğilimi söz konusudur. Fiziksel aktivitenin, bulaşıcı olmayan çeşitli kronik hastalıkları önlediği, Covid-19 hastalığında sağ kalım oranlarını yükselttiği, hastalık sonrası genel iyilik halini koruduğu ve genel sağlık düzeyini artırarak yaşam kalitesine büyük katkı sağladığı bilinmektedir. $\mathrm{Bu}$ nedenlerle fiziksel aktivitenin değerlendirilmesi büyük önem kazanmakta, bu konuda birçok objektif ve subjektif fiziksel değerlendirme yönteminin olması da bu yöntemlerin protokollerinin, avantaj ve dezavantajlarının detaylı irdelenme ihtiyacını oluşturmaktadır. Fiziksel aktivite değerlendirmesinin güncel ve kapsamlı bir literatür derlemesi ile ele alınması, klinisyenlerde oluşabilecek bazı kafa karışıklıklarının ve değerlendirme yöntemi ile ilgili seçim zorluklarının üstesinden gelinmesinde yardımcı olacaktır.

Anahtar Kelimeler: Anket, Covid-19, fiziksel aktivite, sensör

Mehmet ÖZKESKIN (西)

Ege Üniversitesi, Sağllk Bilimleri Fakültesi, Fizyoterapi ve Rehabilitasyon Bölümü, 35100, Bornova/İzmir/Türkiye.

e-mail:mehmet.ozkeskin76@gmail.com

${ }^{l}$ Ege Üniversitesi, Sağllk Bilimleri Enstitüsü, Fizyoterapi ve Rehabilitasyon $A B D$.

${ }^{2}$ Muğla Sıtkı Koçman Üniversitesi, Köyceğiz SHMYO, Yaşlı Bakımı Bölümü.

${ }^{3}$ Ege Üniversitesi, Sağllk Bilimleri Fakültesi, Fizyoterapi ve Rehabilitasyon Bölümü

\section{ABSTRACT}

Physical activity is an essential parameter associated with general health status. Recently, there has been an increasing trend of physical inactivity due to the Covid-19 pandemic, where quarantine measures have been taken. It is known that, physical activity prevents various non-communicable chronic diseases, increases survival rates in Covid-19 disease, maintains general well-being after the illness, and contributes greatly to quality of life by increasing the general health level. For these reasons, the evaluation of physical activity gains great importance, and the fact that there are many objective and subjective physical evaluation methods in this regard creates the need for detailed examination of the protocols, advantages and disadvantages of these methods. Addressing physical activity assessment with an up-to-date and comprehensive literature review will help to overcome some of the confusions that may occur in clinicians and the selection difficulties related to the assessment method.

Keywords: Questionnaire, Covid-19, physical activity, sensor

\section{FİZIKSEL AKTİVITE DEĞERLENDİRMESİ: SUBJEKTİF VE OBJEKTİF YÖNTEMLER}

Fiziksel aktivite, kas iskelet sisteminin çalışması sonucunda enerji harcanması olarak tanımlanabilir. Fiziksel aktivite kavramı tarihsel süreçte de önemli bir yere sahip olmuştur. Hipokrat, "Regimen in Health" isimli kitabında "Sadece yemek bir kişinin sağlığını korumaya yeterli değildir, ayrıca egzersiz yapmalıdır" ifadesi ile fiziksel aktivitenin genel sağlık durumu ile ilişkisine değinmiştir (1). Küresel verilere göre, yetişkinlerin $\% 27,5$ 'inin ve ergenlerin \%81'inin Dünya Sağlı Örgütü (DSÖ) 2010 yılı fiziksel aktivite tavsiyelerini karşılamadığı görülmüştür (2). Bu fiziksel inaktivite tablosuna teknolojinin gelişmesi, ulaşılabilirliğin artışı gibi nedenler sebep olabilmektedir (3). 
Düzenli fiziksel aktivite, birçok kronik hastalıkta morbiditeyi azaltmak ve erken mortalite riskini önlemek için etkili bir koruyucu önlem olmaktadır (4). Buna ek olarak düzenli fiziksel aktivite öz yeterliliği geliştirerek depresif belirtilerin ortaya çıkmasını önleyebilmektedir. Kognitif fonksiyonlara etkisi açısından bakıldığında da, orta derecede rekreasyonel fiziksel aktivitenin 15 ylllık takipte daha düşük demans insidansı ile ilişkili olduğu gösterilmiştir $(5,6)$.

Fiziksel aktivitenin genel iyilik hali açısından önemi özellikle Covid-19 pandemi sürecinde daha iyi anlaşılmıştır. Karantina döneminde yapılan güncel bir çalışmada İran toplumunda Covid-19 salgınının fiziksel aktivitede azalmaya yol açtığı bildirilmiştir (7). Almanya, İtalya, Rusya ve İspanya toplumlarında yapılan bir diğer çalışmada ise Covid-19 pandemisi nedeniyle, depresyon semptomları olan bireylerin psikolojik yüklerinin artış gösterdiği belirtilmiştir. Bununla birlikte, fiziksel aktivitenin bu olumsuz etkiyi azaltabileceği de bildirilmiştir (8). Bireylerin fiziksel aktivite seviyeleri yüksek olduğunda hastalığı ağır geçiren vaka sayılarının ve ölüm oranının azaldığı bildirilmiştir (9).

Fiziksel aktivitenin değerlendirilmesi toplum sağl açısından büyük öneme sahiptir. Bu değerlendirme ile genel toplumda sağlığın bozulma riskini azaltmak, en uygun egzersiz dozunu belirlemek ve bireye özgü egzersiz reçetesi sağlamak hedeflenir (10). Fiziksel aktivite objektif ve subjektif araçlar ile kapsamlı bir şekilde değerlendirilebilmektedir. Çalışmamızın amacı güncel gelişmeleri de göz önüne alarak, sağlık profesyonellerinin ve araştırmacıların yararlanabilecekleri subjektif ve objektif fiziksel aktivite değerlendirme yöntemlerinin derlenerek ele alınmasıdır.

\section{SUBJEKTIF FİZIKSEL AKTIVITE ÖLÇÜM ARAÇLARI}

Fiziksel aktivite düzeyinin değerlendirmesi ve inaktiviteye bağlı sağlık ile ilişkili risklerin anlaşılmasına önemli ölçüde katkıda bulunan anketler ve etkinlik günlükleri gibi bireylerin kendi durumları ile ilgili bireysel bildirimde bulundukları araçlar, subjektif değerlendirmelerin temelini oluşturmaktadır. $\mathrm{Bu}$ anket ve skalalar, yanıtlayan bireyler için fazla iş yükü oluşturmamaktadır ancak subjektif ifadeler içerdiğinden oldukça değişkenlik gösterebilir. Fiziksel aktivite ve inaktif geçirilen sürenin hem olduğundan fazla hem de olduğundan düşük gösterilmesine yol açabilir (10). Avantaj ve dezavantajları olmasına rağmen objektif yöntemlere göre ulaşılabilirlik, maliyet ve kolay kullanım özellikleri sayesinde sık tercih edilen bir veri toplama yöntemidir.

- Uluslararast Fiziksel Aktivite Anketi: $\mathrm{Bu}$ anket, Dünya Sağlik Örgütü (World Health OrganizationWHO) ve Hastalık Kontrol Merkezleri (Centers for Disease Control-CDC)'nin desteğiyle çeşitli ülkelerden araştırmacılar tarafindan geliştirilmiş, fiziksel aktiviteyi ölçmek için standardize edilmiş bir araçtır (11). Anketin hem uzun hem de kısa formunun Türkçe versiyonunun geçerlilik ve güvenilirliği Sağlam ve ark. (11) tarafından yapılmıştır. Uzun formunda 27 madde ve kısa formunda 7 madde vardır. Anket, fiziksel aktivitenin dört alanı olan; iş, ulaşım, ev işi/bahçe işleri ve boş zaman aktivitelerini kapsamakta aynı zamanda inaktivitenin bir göstergesi olarak oturarak geçirilen zamanla ilgili soruları da içermektedir. Dört alanın her birinde orta ve şiddetli aktivitelerde son 7 gün içinde harcanan enerji, aktivitelerin yapıldığı gün sayısı ve aktivitelerin gün içinde ne kadar gerçekleştirildiği kaydedilir. Süreler, aktivite başına Metabolik Eşdeğer (MET) değerleri ile çarpılır ve tüm ögelerin sonuçları genel fiziksel aktivite skorunu oluşturmak üzere toplanır. Fiziksel aktivite puanına oturma ile ilgili olan soru dahil edilmez. Fiziksel olarak inaktif $(<600 \mathrm{MET} \mathrm{dk} / \mathrm{hafta})$, fiziksel aktivite düzeyi az (600-3000 MET dk/hafta), fiziksel aktivite düzeyi yeterli (>3000 MET dk/hafta) olmak üzere üç kategoride sınıflandırma yapılmaktadır (11-13).

- Gebelik Fiziksel Aktivite Anketi: Hamile kadınların fiziksel aktivite düzeylerinin değerlendirilmesi için kullanılan bir ankettir. Çırak ve ark. (14) ile Tosun ve ark. (15) tarafindan bu anketin Türkçe versiyonunun geçerlilik ve güvenilirliği yapılmıştır. Gebelik Fiziksel Aktivite Anketi, katılımcılardan ev/bakım (13 aktivite), meslek (5 aktivite), spor/egzersiz (8 aktivite), ulaşım (3 aktivite) ve inaktivite (3 aktivite) dahil olmak üzere 32 aktiviteye katılmak için harcanan zamanı rapor etmelerini isteyen bir ankettir. Katılımcılardan, içinde bulundukları trimestere göre, her bir aktivite için günde veya haftada harcamış oldukları süreye en yakın kategoriyi seçmeleri istenir. Fiziksel aktivite süresi "günde 0 ila 6 saat arasında veya daha fazla" ile haftada " 0 ila 3 saat veya daha fazla" seçenekleri ile sorgulanmaktadır. Anketin sonunda, açık uçlu bir bölüm mevcuttur. Ankette, her aktivite için ortalama günlük enerji harcaması (günlük MET-saat) değerine ulaşmak için her aktivitede harcanan saat sayısı aktivite yoğunluğu ile çarpılmaktadır $(14,16)$. 
- Büyük Çocuklar İçin Fiziksel Aktivite Anketi: Adölesan bireylerde fiziksel aktiviteyi ölçmek için oluşturulmuş bir ankettir. Erdim ve ark. (17) tarafından bu anketin Türkçe versiyonunun geçerlilik ve güvenilirliği yapılmıştır. Günümüzde çocuklar ve gençler fiziksel inaktivite sınırlarında daha fazla yer almaktadır. Üstelik çocuklarda ve ergenlerde fiziksel aktivite ilişkisinin belirlenmesi daha zordur $(17,18)$. Bu nedenle bu yaş gruplarına özel fiziksel aktivite değerlendirme yöntemleri de elzemdir. Ölçeği oluşturan 10 maddeden 9'u aktivite puanlarının hesaplanmasında kullanılmaktadır. 10. madde, çocuğun hasta olmasına veya başka bir engeli olmasına rağmen önceki hafta normal aktivitede bulunup bulunmadığını değerlendirir. Ancak bu madde, aktivite puanı hesaplamasına dahil edilmemektedir. Büyük Çocuklar İçin Fiziksel Aktivite Anketi ile ilgili ilk soru, yirmi iki adet yaygın boş zaman ve spor aktivitesini içeren bir aktivite kontrol listesi biçimindedir. Bu soruya verilen yanitlar 5 puanlık bir derecelendirmeye göre değerlendirilir (1=hiç etkinlik yok, 5=yedi defa veya daha fazla yaptım). Yüksek puan, daha yüksek fiziksel aktiviteyi gösterir (17-19).

- Yaşlılar İçin Fiziksel Aktivite Skalası: Yaşlılar İçin Fiziksel Aktivite Skalası, 65 yaş ve üzeri bireylerde fiziksel aktiviteyi değerlendirmek için özel olarak tasarlanmış kısa yapıda ve kolay puanlanabilen bir ankettir (20). Ölçeğin Türkçe versiyonunun geçerlilik ve güvenilirliği Ayvat ve ark. (21) tarafından yapılmıştır. Ölçek, bir haftalık bir zaman dilimi boyunca yaşlı bireylerde fiziksel aktiviteyi değerlendirir. Ev dışında yürümek dahil boş zaman etkinliklerine, spor, eğlence ve kas kuvvetlendirme aktivitelerine katılım kaydedilir. Süre 1 saatten az, 1 ile 2 saat arasinda, 2-4 saat veya 4 saatten fazla olarak kategorize edilir. Çoğunlukla oturma aktivitesini içeren işler dışındaki ücrete tabi veya ücrete tabi olmayan iş ile ilgili faaliyetler, haftalık toplam saat olarak kaydedilir. Ev işleri (hafif ve ağır), çim/bahçe bakımı, ev onarımı, dış mekân aktiviteleri ve bakım ile ilgili faaliyetler evet/hayır seçenekleri ile ifade edilmektedir. Toplam ölçek puanı, her bir aktivitede harcanan zamanın (saat/hafta) veya bir aktiviteye katılımın (evet/hayır) deneysel olarak elde edilmiş madde değerleri ile çarpılması ve tüm aktivitelerin toplamı ile hesaplanmaktadır. Yüksek skor, daha iyi fiziksel aktivite seviyelerini gösterir $(20,21)$.

- LASA Fiziksel Aktivite Anketi: Yaşlı bireyler için geliştirilen bir fiziksel aktivite anketidir. Türkçe versiyonunun geçerlilik ve güvenilirliği Aydoğan Arslan ve ark. (22) tarafından yapılmıştır. LASA Fiziksel Aktivite Anketi, açı havada yürüyüş, bisiklet, bahçe işleri, hafif ev aktiviteleri, ağır ev aktiviteleri, spor ve ileri düzeyli yaşam aktivitelerini kapsayan bir ankettir. Son iki haftada gerçekleştirilen faaliyetler sorgulanmaktadır. Toplam 31 soru içermektedir. Ankette puanlama aktivitelerin süresine göre yapılır; aktivite süreleri günde 0, 1-15, $16-30,31-60$ ve $61-120$ dakika ve $>120$ dakika olarak sinıflandırılır ve sirasıyla $0,1,2,3,4,5$ olarak puanlanır. İki hafta içindeki toplam skor, aktivitenin sıklığ ve zaman skoru çarpılarak hesaplanır. Yüksek puanlar daha iyi fiziksel aktivite seviyelerini göstermektedir $(22,23)$.

- Global Fiziksel Aktivite Anketi: Uluslararas1 Fiziksel Aktivite Anketi'nin uzun formu sağlık araştırmalarında kullanmak için çok uzun ve karmaşık olarak kabul edilmiştir. Kısa formu ise fiziksel aktivite üzerinde fark oluşturabilecek çeşitli verileri algılayamamasından dolayı kısıtlı bulunmuştur (24). Bu nedenlerden dolayı, Dünya Sağlık Örgütü tarafından, Global Fiziksel Aktivite Anketi geliştirilmiştir. Bununla birlikte geliştirilen Global Fiziksel Aktivite Anketi'nin Türkçe versiyon geçerlilik ve güvenilirliği henüz yayınlanmamıştır. Anket, iş için yapılan fiziksel aktiviteyi (ücrete tabi olan veya olmayan), ulaşımı (belirlenen yere gitmek için yürüme veya bisiklete binme), eğlence etkinliklerini, rekreasyonel aktiviteleri ve inaktivitede harcanan zamanı ölçen 16 maddeden oluşur. Ulaşım alanı için, yürüyüş ve bisiklete binme ile ilgili bilgiler toplanır. Aktiviteler üç yoğunluk seviyesinde sınıflandırılır: inaktivite (1 MET), orta şiddet (4 MET) ve yüksek şiddet (8 MET) $(24,25)$.

- European Health Interview Survey Fiziksel Aktivite Anketi: Özkeskin ve ark. (26) tarafindan anketin Türkçe versiyonunun geçerlilik ve güvenilirliği yapılmıştır. $\mathrm{Bu}$ anket, iş, ulaşım ve boş zamanlardaki fiziksel aktiviteleri (spor aktiviteleri dahil), tipik bir hafta boyunca aerobik sağlığı güçlendirici ve kas güçlendirici fiziksel aktiviteleri kapsayan 8 maddeden oluşur. Katılımcıların tipik bir hafta boyunca boş zaman sporları veya kas güçlendirme aktivitelerinde geçirdikleri toplam süre kaydedilir. Son soru, katılımcıların kas güçlendirici fiziksel aktivite uyguladıkları süreyi sorgulamaktadır. $(27,28)$.

- Bouchard Fiziksel Aktivite Günlü̈ğ̈̈: Fiziksel aktivitenin subjektif ölçümünü yapmak için çocukları ve yetişkinleri içeren çalışmalarda kullanılmıştır (29). Bouchard ve ark. (30) tarafından geliştirilmiştir. Bu aktivite günlüğü fiziksel aktivite değerlendirmesi, deri kıvrım kalınlıkları 
ve vücut yağ yüzdesi toplamı gibi temsili değerleri ile çocuklarda ve yetişkinlerde doğrulanmıştır (31). Bir günü 96 tane 15 dakikalık periyotlara bölen bir veri formunu içermektedir. Katılımcılardan, her 15 dakikalık periyotta gerçekleştirdikleri birincil aktivitenin yoğunluğunu sayısal bir aktivite kodu kullanarak (1'den 9'a kadar) derecelendirmeleri istenir. Etkinlik kodları 1-3 hareketsizliği ( $<2.8 \mathrm{MET})$ temsil ederken, 6-9 kodları orta-şiddetli fiziksel aktiviteyi ( $\geq 4.8$ MET) temsil eder. Her 15 dakikalık aralık için tahmini enerji harcaması hesaplanır ve 96 tane aralığın toplamı, toplam günlük enerji verimliliğinin bir tahminini elde etmek için kullanılır. Bouchard günlüğü, günlük enerji verimliliğini tahmin etmek için genellikle ortalama 3 gündeki veriden faydalanmaktadir $(29,31)$.

- Frenchay Aktivite Índeksi: Ev içi aktivite, iş/boş vakit ve açık hava aktiviteleri kategorilerinde kompleks etkinlikleri ölçen 15 maddeden oluşur. Değerlendirme skoru, 0 (aktif değil) ile 45 (çok aktif) arasında değişir. İlk 10 madde son üç ayda, kalan maddeler ise son altı ayda gerçekleştirilen faaliyetlerin sıklığını ifade eder. Her madde 4 puanlı likert ölçeğinden oluşur $(0=a$ ala, $3=$ en az haftada bir kez) ve toplam puanlama şu şekilde sinıflandırılabilir: 0-15=aktif değil; $16-30=$ orta derecede aktif ve 31-45=çok aktif. Frenchay Aktivite İndeksi'nin inme geçiren hastalarda da geçerli olduğu gösterilmiştir $(32,33)$.

- Insan Aktivite Profili (Human Activity Profile-HAP): 94 aktivite maddesinden oluşur. Kronik obstrüktif akciğer hastalığı olan hastaların aktivite düzeylerini ölçmek için geliştirilmiştir. Farklı yaşlarda kronik hastalığı olan bireylerde de kullanılabilen bir ölçektir. Aktiviteler 94 maddede, düşükten yüksek enerjili aktivitelere doğru sıralanmaktadır. Her aktivite maddesi 3 olası cevap içerir ("halen yapıyorum", "yapmayı bıraktım" ve "hiç yapmadım"). Puanlar katılımcının "halen yapıyorum" seçeneğini işaretlediği en yüksek madde numarası baz alınarak belirlenir. Anketi tamamladıktan sonra, maksimum aktivite puanı ve düzeltilmiş aktivite puanı elde edilir. Maksimum aktivite puanı, en çok çaba gerektiren ve halen birey tarafindan uygulanan aktiviteleri temsil etmektedir. Anket, 0 ile 94 arasinda değerler almakta ve yüksek puanlar daha fazla fiziksel aktivite anlamına gelmektedir. Bireyin fiziksel aktivite düzeyi, düzeltilmiş aktivite puanına göre üç alt gruptan birine girer: $<53$ puan: yetersiz aktivite düzeyi, 53-74 puan: orta derecede aktif ve $>74$ puan: aktif (34-36).
- Stanford Kısa Aktivite Anketi Bireylerin gün boyunca halihazırda gerçekleştirdiği fiziksel aktivitenin olağan miktarı ve yoğunluğu hızlı bir şekilde değerlendirilebilmektedir. Anket iki madde içerir. İlk madde çeşitli işlerdeki aktivite türlerini tanımlarken, ikinci madde çeşitli boş zaman aktivitelerini tanımlamaktadır. Her öğenin beş yanıt seçeneği vardır. Her yanıt seçeneği sıklık, yoğunluk, zaman ve aktivite tipleri hakkında genel bir ifade içerir. Aktivite kategorisi, 5 farklı aktivite kategorisini (inaktif, hafif, orta, zor ve çok zor yoğunluk) temsil eden renk kodlu bir puanlama tablosu kullanılarak belirlenir. (37).

- 7 Gün Fiziksel Aktivite Günlüğ̈̈: Her gün 15 dakikalık 96 aralığa bölünmekte ve katılımcılar etkinliklerini dokuz kategoriye ayırmaktadır. Fiziksel aktivite günlüğü aktivite seviyesi (PAD) 1-9 arasında derecelendirilmiştir. Burada PAD1 uykuyu, PAD2 oturmay1, PAD3 ayakta durmayı, PAD4 içeride yürümeyi, PAD5 dişarıda yürümeyi ve PAD6-PAD9 ise sırasıyla düşük, orta, yüksek ve maksimum yoğunluklu aktiviteyi temsil etmektedir. Aktivite seviyeleri, Bratteby ve ark. (38) tarafindan belirlenen metabolik eşdeğerler (MET) kullanılarak tayin edilmektedir. 7. Gün sonunda aktivite günlükleri toplanır ve katılımcı ile birlikte gözden geçirilir. Her bir PAD için 15 dakikalık periyotlar toplanır sonra katılımcıların sabah uyandıktan 30 dakika sonra bir başlıklı kalorimetre ile yapılan iki ölçümün ortalaması olan "RMRmeas" değeri ve Bratteby ve ark. (39) belirlediği bir çarpma faktörü ile birlikte çarpılarak bir toplam enerji harcaması elde edilir.

\section{OBJEKTIF FİİKSEL AKTIVITE ÖLÇÜM ARAÇLARI}

Objektif ölçüm araçları, subjektif yöntemlerdeki bazı sınırlamalarının aksine minimum enerji harcamasıyla ortaya çıkan fiziksel aktiviteyi daha net sunmaktadır. Objektif yöntemlerin, enerji harcamasına ilişkin daha kesin tahminler sunduğuna, fiziksel aktivite parametrelerini olduğundan az ya da çok gösterme hatasını ve yanıt yanlılığı sorunlarının çoğunu ortadan kaldırdığına inanılmaktadır. Objektif yöntemleri kullanmanın avantajlarına rağmen, bu tür yöntemler genellikle zaman ve maliyet açısından sorun oluşturmaktadır. Ayrıca, bu yöntemler kişiye özel eğitim ve veri toplama için katılımcıya birebir ulaşım gerektirdiği için pratikte uygulanması daha zor olabilir (4)

- Akselerometre: İvmeölçerler bir veya daha fazla düzlemde yerçekimi ivme birimlerini kaydeden küçük 
giyilebilir izleme aygitlarıdır. Farklı markalarda, farklı eksenli (genellikle antero-posterior, mediolateral ve vertikal), farklı algoritmalara sahip, farklı hafıza kapasiteli çeşitleri mevcuttur. İvmeölçerler kalça, femur bölgesi ve ayak bileği başta olmak üzere vücudun farklı kısımlarına giyilebilir. Bu farklılıklar, çeşitli fiziksel aktivitelerin algılanması açısından minimal farklılıklar oluşturabilmektedir. İvmeölçerlerin en belirgin limitasyonlarından biri, ağırlık kaldırma gibi ambulatuar olmayan aktiviteleri ölçmede eksik kalmasıdır. Klinisyenler aktivite çeşitlerine göre cihazın vücuttaki konumunu da dikkate almalıdır. Geleneksel olarak çoğu çalışma ivmeölçeri, bel çevresinde elastik bir kemerde veya sağ kalça üzerinde konumlandırmıştır. Yakın zamanda yapılan çalışmalarda ivmeölçerlerin ayak bileğine yerleştirilmesi de tavsiye edilmiştir (42). Bilek yerleşimi en azından çocuklar arasında daha iyi uyuma yol açsa bile, kalça yerleşiminin laboratuvar ortamında enerji tüketimini daha iyi yansıttığı gösterilmiştir (43). Femur bölgesi yerleşimi kullanmanın avantajı ise, femurun statik eğimini ölçme avantajıdır. Bu sayede oturmayı ve yatmayı ayakta durmaktan, düz yürümeyi merdivende yürümekten de daha iyi ayırt edebilme olasılı̆̆1 söz konusudur. Bunun için eğim ölçer içeren ActivPal $^{\mathrm{TM}}$ gibi cihazlar kullanılmaktadır.

- Ölçüm protokolünün bir diğer adımı sonuçları toplamadan önce gerçek aktivite verilerinden yanlış verileri ve giyilmemiş süreyi ayırmayı ifade eder. Yanlış veriler, vücuttaki aktivite izlem araçlarının yanlış konumları, hatalı donanım kalibrasyonu veya arıza nedeniyle aşırı değerler veya sistematik olarak yanlış değerler içermesidir. Önceden ayarlanmış bir kesme noktasının üzerindeki değerlere sahip tüm sinyaller hariç tutularak aşırı değerler bulunabilir. Giyilmemiş süre, aktivite izlem aracının çıkarıldığı ve hareketin olmadığı (aktivite izlem aracını bir masaya koyarken olduğu gibi) veya çıkarılıp bir çantaya konulduğu dönemlerdir. $\mathrm{Bu}$ dönemlerde hareketler hala kaydedilmektedir. Optimum kullanım (saat ve gün açısından) konusunda fikir birliği yoktur $(10,36,44-46)$.

- Pedometreler (Adımsayarlar): İvmeölçerlere göre daha basit ve daha uygun maliyetli bir alternatiftir. Pedometrelerin başlıca avantajları, kullanım kolaylıklarını içerir. Çünkü cihazı kullanmak ve çıktıyı yorumlamak çok az teknik uzmanlık gerekir. Çoğu pedometre kalçaya takılmak üzere tasarlanmış olsa da adımları algılamak için en doğru yerleşimin ayak bileği olabileceği vurgulanmaktadır. Adımsayarların doğruluğu, daha yavaş yürüme hızlarında ( $\leq 2 \mathrm{mph}$ ), diğer monitör yerleşimlerinde (örneğin, el bileği, cep) ve daha yaşlı yetişkinler ile yürüme bozukluğu olanlar arasında ölçüm sıkıntısı oluşturabilir. Adımsayarların dezavantajları, ambulatuar olamayan aktiviteleri, postürü, enerji tüketimini ölçememeleri ve adımları belirlemek için özel algoritmalara ihtiyaç duymalarıdır (10, 45-48).

- Çift İşaretli Su Yöntemi (Doubly Labeled Water): Toplam enerji harcamasının değerlendirilmesinde altın standarttır. Yöntem, solunum $\mathrm{CO}_{2}$ 'sindeki oksijenin vücut sıvısındaki oksijen ile tam izotopik dengede olduğu gözlemine dayanmaktadır. Böylece vücut sıvısına verilen izotopik olarak işaretlenmiş oksijen hem su hem de $\mathrm{CO}_{2}$ olarak elimine edilir (49).

- Kalp Atım Hızı Monitörü: Enerji tüketimini tahmin etmek için kalp atış hızının kullanılmasının kökeni, laboratuvar koşullarında, yürüyüş, koşu, bisiklet aktivitelerinin çoğunda kalp atış hızı ve oksijen alımı arasında doğrusal bir ilişki olduğunu gösteren Berggren ve Christensen'in çalışmalarına dayanmaktadır (50). Kalp atım hızı monitörleri en yaygın direkt fizyolojik ölçüdür. Genel hata oranları tipik olarak $<\% 3$ 'tür (51). Kalp atım hızı monitörü bisiklete binme, yüzme ve diğer ambulatuar olmayan aktiviteler dahil olmak üzere bir ivmeölçer ile iyi ölçülemeyen aktiviteler için mükemmel seçeneklerdir. Kalp atım hızı monitörlerinin mevcut sınırlamalarından bazıları, kan basıncını azaltan ilaçlar ve cihazı uzun süre kullanmanın olası rahatsızlığı olarak sayılabilir. Önceki bölümde belirtildiği gibi, kalp atış hızının fiziksel aktivite bağlamında yorumlanması karmaşıktır. Ayrıca nabız sadece kişinin metabolizmasından ve postüral aktivitesinden değil, aynı zamanda onun geçici duygusal durumundan, iklim koşullarından ve aktiviteyi gerçekleştiren kas gruplarından da etkilenir. Aktivitenin bitmesinden bir süre sonra da kalp hızının yükselmeye devam etmesi algılanan fiziksel aktivite düzeyini artırabilmektedir.

- Kalp hızı, fiziksel aktivitenin doğrudan bir ölçüsü değil, aktivite tarafindan kardiyopulmoner sistem üzerine etkiyen göreceli stresin bir ölçüsüdür. Kalp hızı ve fiziksel aktivite arasındaki ilişki bu nedenle orta ile şiddetli fiziksel aktivite seviyelerinde düşük aktivite seviyelerine göre daha güvenlidir. Önceden belirlenmiş ortalama bir değerin altındaki ve üstündeki kalp atım hızı oranlarının spesifik belirlenmiş bir denklem ile hesaplanması klinisyenler tarafindan fiziksel aktivite 
değerlendirmesinde kullanılır. Elde edilen verilerin değerlendirilmesinde kullanılan yöntemlerden birisi, maksimum kalp hızı veya kalp hızı rezervinin belirli bir yüzdesinin üzerinde seyreden dakikanın belirlenmesidir. İkinci bir yöntem, aktivite kalp hızının temel kalp hızından çıkarılması ile elde edilir. Ancak, bu yöntem enerji harcamasının tahminine uygun değildir. Üçüncü bir yöntem, "FLEX kalp atım hızı" yöntemi olarak adlandırılır. Bu yöntem zaman alıcı ve maliyetlidir (52$54)$.

- Çoklu Sensör Sistemleri: Çoklu sensör sistemleri, daha hassas fiziksel aktivite ölçümleri sağlamak için çoklu fizyolojik ve mekanik sensörleri birleştirir. Parametreler arasında ivme ölçümü (birden fazla yerleşimde), kalp atış hızı, galvanik cilt yanıtı, solunum, cilt 1sısı, biyoempedans ve diğer araçlar yer alabilir. Çoklu sensör sistemlerinin avantajları, birden fazla sensörden gelen enerji harcaması tahminlerinin özellikle ambulatuar olmayan aktivitelerde daha fazla kesinlik sağlamasıdır. Altın standart kabul edilen objektif giyilebilir bir monitör yoktur. Objektif giyilebilir monitörlerin seçiminin, ilgilenilen spesifik fiziksel aktivite bileşeni, teknolojideki gelişim ve algoritma gelişimi dahil olmak üzere birçok faktöre bağlı olması gerektiği belirtilmektedir (10).

\section{- Kalorimetre}

Direkt Kalorimetre: Mevcut enerji harcamasının en kesin ölçüsü doğrudan kalorimetridir. Bu yöntemde, bir kişi kapalı bir odada değerlendirilir. Kalori harcaması 1S1 üretimi ile belirlenir. Doğrudan kalorimetri, \%1'den daha az hataya sahiptir. Normal aktiviteyi açık bir şekilde limitler, bu nedenle diğer fiziksel aktivite değerlendirme yöntemlerini doğrulamak için son derece doğru bir araç olarak kullanılmaktadır (55).

Indirekt Kalorimetre: İndirekt kalorimetre, solunan havayı analiz ederek oksijen tüketimini ölçmeyi içerir. İndirekt kalorimetrede bildirilen hata $\% 2$ ila 3 'tür. Direkt kalorimetreden daha pratik olmasına rağmen, bu yöntemin hala normal aktivite paternlerini sınırladığı ifade edilmektedir (55).

Sonuç olarak; fiziksel aktivite değerlendirmesinde geçerli ve güvenilir birçok subjektif ve objektif yöntemler mevcuttur. $\mathrm{Bu}$ yöntemler sayesinde değerlendiriciler kişilerin günlük yaşamı boyunca kompleks sayılabilecek fiziksel aktivite düzeylerini tahmin etmede daha başarılı olabilmektedir. Subjektif ve objektif yöntemlerin birbirlerine göre avantaj ve dezavantajları bulunmaktadır, bunların iyi bilinmesi duruma özel fiziksel aktivite tahmininde değerlendiriciye büyük katkı sağlayabilir, bireylerin günlük yaşamdaki aktüel fiziksel aktivite düzeyinin tahmininde oluşabilecek eksiklik ya da fazlalıkları en aza indirmek mümkün olabilir. Bu değerlendirme araçlarının her birini kullanırken dikkat edilmesi gereken en önemli husus, kişiye ve fiziksel aktivite çeşidine özel seçim yapmaktır. $\mathrm{Bu}$ faktörlerin klinisyenler tarafindan iyi analiz edilerek uygun değerlendirme yönteminin seçilmesi de büyük önem taşımaktadır.

\section{KAYNAKLAR}

1. Dishman RK, Heath GW, Schmidt MD, Lee IM. Physical Activity Epidemiology. 3th ed. [Internet]. USA: Human Kinetics; 2021. 1-10 p.

2. World Health Organization (WHO). WHO guidelines on physical activity and sedentary behaviour: at a glance. Geneva, Switzerland, 2020. PDF dokümanı [Date of access: 3 Haziran 2021]

3. Woessner MN, Tacey A, Levinger-Limor A, Parker AG, Levinger P, Levinger I. The Evolution of Technology and Physical Inactivity: The Good, the Bad, and the Way Forward. Front. Public Health. 2021;9:672.

4. Warburton DER, Bredin SSD. Reflections on Physical Activity and Health: What Should We Recommend? Can J Cardiol. 2016;32(4):495-504. doi: 10.1016/j. cjca.2016.01.024.

5. Kandola A, Ashdown-Franks G, Hendrikse J, Sabiston CM, Stubbs B. Physical activity and depression: Towards understanding the antidepressant mechanisms of physical activity. Neurosci Biobehav Rev. 2019;107:525-39. doi: 10.1016/j.neubiorev.2019.09.040.

6. Feter N, Mielke GI, Leite JS, Brown WJ, Coombes JS, Rombaldi AJ. Physical activity in later life and risk of dementia: Findings from a population-based cohort study. Exp Gerontol. 2021;143:111145. doi: 10.1016/j. exger.2020.111145.

7. Amini H, Isanejad A, Chamani N, Movahedi-Fard F, Salimi F, Moezi M, et al. Physical activity during COVID-19 pandemic in the Iranian population: A brief report. Heliyon. 2020;6(11):e05411. doi: 10.1016/j.heliyon.2020.e05411.

8. Brailovskaia J, Cosci F, Mansueto G, Miragall M, Herrero $\mathrm{R}$, Baños RM, et al. The association between depression symptoms, psychological burden caused by Covid-19 and physical activity: An investigation in Germany, Italy, Russia, and Spain. Psychiatry Res. 2021;295:113596. doi: 10.1016/j. psychres.2020.113596.

9. Cunningham GB. Physical activity and its relationship with COVID-19 cases and deaths: Analysis of U.S. counties. J Sport Health Sci. 2021. doi: 10.1016/j.jshs.2021.03.008.

10. Ainsworth B, Cahalin L, Buman M, Ross R. The Current State of Physical Activity Assessment Tools. Prog Cardiovasc Dis. 2015;57(4):387-95. doi: 10.1016/j.pcad.2014.10.005. 
11. Saglam M, Arikan H, Savci S, Inal-Ince D, Bosnak-Guclu M, Karabulut E, et al. International physical activity questionnaire: reliability and validity of the Turkish version. Percept Mot Skills. 2010;111(1):278-84.

12. Hagströmer M, Oja P, Sjöström M. The International Physical Activity Questionnaire (IPAQ): a study of concurrent and construct validity. Public Health Nutr. 2006;9(6):755-62. doi: 10.1079/PHN2005898.

13. Savc1, S., Öztürk, M., Arıkan, H., İnal İnce, D., \& Tokgözoğlu, L. Üniversite öğrencilerinin fiziksel aktivite düzeyleri. Turk Kardiyol Dern Ars, 2006;34(3):166-72.

14. Çırak Y, Yılmaz GD, Demir YP, Dalkılınç M, Yaman S. Pregnancy Physical Activity Questionnaire (PPAQ): reliability and validity of Turkish version. J Phys Ther Sci. 2015;27(12):3703-9.

15. Tosun OC, Solmaz U, Ekin A, Tosun G, Mutlu EK, Okyay E, et al. The Turkish version of the pregnancy physical activity questionnaire: cross-cultural adaptation, reliability, and validity. J Phys Ther Sci. 2015;27(10):3215-21.

16. Chasan-Taber L, Schmidt MD, Roberts DE, Hosmer D, Markenson G, Freedson PS. Development and validation of a pregnancy physical activity questionnaire. Med Sci Sports Exerc. 2004;36(10):1750-60.

17. Erdim L, Ergün A, Kuğuoğlu S. Reliability and validity of the Turkish version of the Physical Activity Questionnaire for Older Children (PAQ-C). Turk J Med Sci. 2019;49(1):162-9.

18. Crocker PRE, Bailey DA, Faulkner RA, Kowalski KC, Mcgrath R. Measuring general levels of physical activity: preliminary evidence for the Physical Activity Questionnaire for Older Children. Med Sci Sports Exerc. 1997;29(10):1344-9.

19. Kowalski KC, Crocker PR, Faulkner RA. Validation of the physical activity questionnaire for older children. Pediatr Exerc Sci. 1997;9(2):174-86.

20. Washburn RA, McAuley E, Katula J, Mihalko SL, Boileau RA. The Physical Activity Scale for the Elderly (PASE): Evidence for Validity. J Clin Epidemiol. 1999;52(7):643-51. doi: 10.1016/S0895-4356(99)00049-9.

21. Ayvat E, Kilinc M, Kirdi N. The Turkish version of the Physical Activity Scale for the Elderly (PASE): its cultural adaptation, validation, and reliability. Turk J Med Sci. 2017;47(3):908-15.

22. Aydoğan Arslan S, Abit Kocaman A, Sertel M, Önal B, Düger T, Demirgüç A. Reliability and validity of the Turkish version of the Lasa Physical Activity Questionnaire (LAPAQ). Osmangazi T1p Dergisi. 2021; 43(4):341 - 348.

23. Stel VS, Smit JH, Pluijm SMF, Visser M, Deeg DJH, Lips P. Comparison of the LASA Physical Activity Questionnaire with a 7-day diary and pedometer. J Clin Epidemiol. 2004;57(3):252-8. doi: 10.1016/j.jclinepi.2003.07.008.

24. Armstrong T, Bull F. Development of the World Health Organization Global Physical Activity Questionnaire (GPAQ). J Public Health. 2006;14(2):66-70. doi: 10.1007/ s10389.006.0024-x.

25. Herrmann SD, Heumann KJ, Der Ananian CA, Ainsworth BE. Validity and Reliability of the Global Physical Activity Questionnaire (GPAQ). Meas Phys Educ Exerc Sci. 2013;17(3):221-35. doi: 10.1080/1091367X.2013.805139.
26. Özkeskin M, Özden F. The reliability and validity of the Turkish version of the European Health Interview SurveyPhysical Activity Questionnaire (EHIS-PAQ). J Basic Clin Health Sci. 2021;5(2):124-33.

27. Finger JD, Tafforeau J, Gisle L, Oja L, Ziese T, Thelen J, et al. Development of the European health interview surveyphysical activity questionnaire (EHIS-PAQ) to monitor physical activity in the European Union. Arch Belg. 2015;73(1):1-11.

28. Baumeister SE, Ricci C, Kohler S, Fischer B, Töpfer C, Finger JD, et al. Physical activity surveillance in the European Union: reliability and validity of the European health interview survey-physical activity questionnaire (EHIS-PAQ). Int J Behav Nutr Phys Act. 2016;13(1):1-10.

29. Wickel EE, Welk GJ, Eisenmann JC. Concurrent validation of the Bouchard Diary with an accelerometry-based monitor. Med Sci Sports Exerc. 2006;38(2):373-9. doi: 10.1249/01. mss.000.018.3344.46077.bb.

30. Bouchard C, Tremblay A, Leblanc C, Lortie G, Savard R, Thériault G. A method to assess energy expenditure in children and adults. Am J Clin Nutr. 1983;37(3):461-7. doi: 10.1093/ajen/37.3.461.

31. Martínez-Gómez D, Wärnberg J, Welk GJ, Sjöström M, Veiga OL, Marcos A. Validity of the Bouchard activity diary in Spanish adolescents. Public Health Nutr. 2010;13(2):2618. doi: 10.1017/S136.898.0009990681.

32. Monteiro M, Maso I, Sasaki AC, Barreto Neto N, Oliveira Filho J, Pinto EB. Validation of the Frenchay activity index on stroke victims. Arq Neuropsiquiatr. 2017;75(3):167-71.

33. Martins JC, Aguiar LT, Nadeau S, Scianni AA, TeixeiraSalmela LF, Faria CDCDM. Measurement properties of self-report physical activity assessment tools for patients with stroke: a systematic review. Braz J Phys Ther. 2019;23(6):476-90. doi: 10.1016/j.bjpt.2019.02.004.

34. Fix AJ, Daughton D. Human activity profile: professional manual. Odessa: Psychological Assessment Resources; 1988. 25 p.

35. Daskapan A, Kurtoglu F, Kilic F, Karakas F, Ozdemir F. The evaluation of physical activity levels in Turkish dialysis patients. Ann Med Res. 2018;25(4):689-94.

36. Bastone, A., Moreira, B., Vieira, R. A., Kirkwood, R. N., Dias, J. M., \& Dias, R. C. Validation of the human activity profile questionnaire as a measure of physical activity levels in older community-dwelling women. J Aging Phys Act. 2014;22(3):348-356. doi: 10.1123/japa.2012-0283.

37. Taylor-Piliae RE, Norton LC, Haskell WL, Mahbouda MH, Fair JM, Iribarren C, et al. Validation of a New Brief Physical Activity Survey among Men and Women Aged 60-69 Years. Am J Epidemiol. 2006;164(6):598-606. doi: 10.1093/aje/ kwj248.

38. Bratteby LE, Sandhagen B, Fan H, Samuelson G. A 7-day activity diary for assessment of daily energy expenditure validated by the doubly labelled water method in adolescents. Eur J Clin Nutr. 1997;51(9):585-91. doi: 10.1038/ sj.ejcn.1600449. 
39. C. rush E, Valencia ME, Plank LD. Validation of a 7-day physical activity diary against doubly-labelled water. Ann Hum Biol. 2008;35(4):416-21. doi: 10.1080/030.144.60802089825.

40. Tolley APL, Ramsey KA, Rojer AGM, Reijnierse EM, Maier AB. Objectively measured physical activity is associated with frailty in community-dwelling older adults: A systematic review. J Clin Epidemiol. 2021;137:218-30. doi: 10.1016/j. jclinepi.2021.04.009.

41. Prince SA, Adamo KB, Hamel ME, Hardt J, Gorber SC, Tremblay M. A comparison of direct versus selfreport measures for assessing physical activity in adults: a systematic review. Int J Behav Nutr Phys Act. 2008;5(1):56. doi: 10.1186/1479-5868-5-56.

42. Doherty A, Jackson D, Hammerla N, Plötz T, Olivier P, Granat $\mathrm{MH}$, et al. Large scale population assessment of physical activity using wrist worn accelerometers: The UK Biobank Study. PLoS One. 2017;12(2):e0169649.

43. Hildebrand M, Van Hees VT, Hansen BH, Ekelund U. Age group comparability of raw accelerometer output from wrist - and hip-worn monitors. Med Sci Sports Exerc. 2014;46(9):1816-24. doi: 10.1249/mss.000.000.0000000289.

44. Arvidsson D, Fridolfsson J, Börjesson M. Measurement of physical activity in clinical practice using accelerometers. J Intern Med. 2019;286(2):137-53. doi: 10.1111/joim.12908.

45. Voss C, Harris KC. Physical activity evaluation in children with congenital heart disease. Heart. 2017;103(18):1408-12. doi: 10.1136/heartjnl-2017-311340.

46. Can S. Fiziksel Aktivite Ölçümü: Objektif ve Sübjektif Yöntemler. Spor Hekimliği Dergisi. 2019;54(4):296-307.
47. Alarie N, Kent L. Chapter 34 - Physical Activity Assessment and Impact. In: Watson RR, editor. Diet and Exercise in Cystic Fibrosis. Boston: Academic Press; 2015. 299-306 p.

48. Corder K, Ekelund U, Steele RM, Wareham NJ, Brage S. Assessment of physical activity in youth. J Appl Physiol. 2008;105(3):977-87. doi: 10.1152/japplphysiol.00094.2008.

49. Speakman JR, Yamada Y, Sagayama H, Berman ESF, Ainslie PN, Andersen LF, et al. A standard calculation methodology for human doubly labeled water studies. Cell Rep Med. 2021;2(2):100203. doi: 10.1016/j.xcrm.2021.100203.

50. Berggren $\mathrm{G}, \mathrm{Christensen} \mathrm{EH.} \mathrm{Heart} \mathrm{rate} \mathrm{and} \mathrm{body} \mathrm{temperature}$ as indices of metabolic rate during work. Arbeitsphysiologie. 1950;14(3):255-60. doi: 10.1007/BF00933843.

51. Ceesay SM, Prentice AM, Day KC, Murgatroyd PR, Goldberg GR, Scott W. The use of heart rate monitoring in the estimation of energy expenditure: A validation study using indirect whole-body calorimetry. Br J Nutr. 1989;61(2):17586. doi: 10.1079/BJN19890107.

52. Westerterp KR. Assessment of physical activity: a critical appraisal. Eur J Appl Physiol. 2009;105(6):823-8. doi: 10.1007/s00421.009.1000-2.

53. Armstrong N. Young people's physical activity patterns as assessed by heart rate monitoring. J Sports Sci. 1998;16(sup1):9-16. doi: 10.1080/026.404.198366632.

54. Freedson PS, Miller K. Objective monitoring of physical activity using motion sensors and heart rate. Res Q Exerc Sport. 2000;71(sup2):21-9.

55. Dishman RK, Washburn RA, Schoeller DA. Measurement of Physical Activity. Quest. 2001;53(3):295-309. doi: 10.1080/ 00336.297.2001.10491746. 